\title{
AVALIAÇÃO E PROPOSTA DE CONECTIVIDADE DOS FRAGMENTOS REMANESCENTES NO CAMPUS DA UNIVERSIDADE FEDERAL DE LAVRAS, MINAS GERAIS
}

\author{
Israel Marinho Pereira ${ }^{1}$, Eduardo van den Berg ${ }^{2}$, Lílian Vilela de Andrade Pinto ${ }^{3}$, \\ Pedro Higuchi ${ }^{4}$, Douglas Antônio de Carvalho ${ }^{2}$
}

(recebido: 25 de agosto de 2009; aceito: 30 de abril de 2010)

\begin{abstract}
RESUMO: Neste trabalho, objetivou-se mapear e caracterizar os fragmentos florestais existentes no domínio da UFLA e identificar potenciais corredores para maximizar a conectividade entre eles. Utilizou-se para confecção do mapa temático o programa SPRING 3.4, a partir de fotos aéreas do ano de 2001 e de imagens de satélite Landsat 7 (março de 2001). Os impactos sofridos pelos fragmentos foram analisados a partir da aplicação de questionários investigativos, a fim de levantar o histórico de intervenções humanas. A flora arbustivo-arbórea dos principais fragmentos foi inventariada pelo método dos quadrantes, tendo como nível de inclusão DAP $\geq 5,0 \mathrm{~cm}$. $\mathrm{O}$ fragmento do museu foi o que apresentou a menor área, a maior influência dos impactos, menor índice de forma e área interna e o maior efeito de borda. Por outro lado, no fragmento da subestação, observou-se a maior área, maior índice de forma e área interna e o menor efeito de borda. Dentre os principais impactos registrados para os fragmentos estudados, destacaram-se: lixo, estradas externas, trilhas e construções. Foram registrados nos quatros fragmentos e nas duas principais unidades de conectividade 544 indivíduos, pertencentes a 48 famílias, 110 gêneros 161 espécies. O maior valor de diversidade foi registrado no fragmento da subestação $(3,917)$ e o menor $(2,135)$ para o fragmento do museu. Após a análise dos resultados, constatou-se a possibilidade de conectividade entre os fragmentos com a recuperação das áreas de preservação permanente no entorno dos cursos d'água e represas e a adoção de medidas que possibilitem minimizar os impactos detectados nesses habitats.
\end{abstract}

Palavras-chave: Efeito de borda, matriz ambiental, ação antrópica, impactos ambientais, corredor ecológico.

\section{EVALUATION AND PROPOSAL OF CONNECTIVITY OF REMNANT FRAGMENTS IN THE CAMPUS OF UNIVERSIDADE FEDERAL DE LAVRAS, MINAS GERAIS}

\begin{abstract}
This paper mapped and characterized the forest remnants in the domain of UFLA and identified potentials corridors to improve the connectivity among them. The thematic map for the analyses was built using the SPRING 3.4 program considering aerial images (2001) and satellite images (Landsat 7, March of 2001). The fragments impacts were analyzed by the application of investigative questionnaires in order to record the past anthropogenic disturbances. The shrub-tree vegetation of the six main fragments was inventoried by the quadrants method, with the inclusion level considering trees with DBH higher or equal to $5.0 \mathrm{~cm}$. The fragments I and IV were respectively the most disturbed fragments. According to the thematic map, the fragment I showed the smallest area, form index and core area, consequently, the largest edge effect. The fragment III showed the largest area, form index and core area and the smallest edge effect. Among the main impacts registered, the most important were garbage, external highways, trails and build constructions. In the six main fragments 544 individuals were registered, belonging to 48 families, 110 genera and 161 species. The largest diversity value was registered in the fragment III (3.917) and the smallest (2.135) in the fragment I. A low similarity was detected among the fragments. After the analysis of the results, the connectivity among the fragments was verified with the recovering of the areas of permanent preservation along the water streams and dams.
\end{abstract}

Key words: Edge effect, environmental matrix, anthropogenic action and environmental impacts.

\section{INTRODUÇÃO}

As florestas tropicais estão incluídas entre os ecossistemas mais ricos em espécies do planeta e pela alta taxa de desmatamento e degradação de seus ambientes, têm sofrido a perda de inúmeras espécies da fauna e flora, pela redução da área de ocorrência e isolamento dos habitats originais, o que resulta na formação de mosaicos

${ }^{1}$ Engenheiro Florestal, Professor Dr. em Engenharia Florestal - Departamento de Engenharia Florestal - Universidade Federal dos Vales do Jequitinhonha e Mucuri/UFVMJ - Rua da Glória, 187 - 39100-000 - Diamantina, MG - imarinhopereira@ gmail.com

${ }^{2}$ Agrônomo, Professor Dr. em Biologia Vegetal - Departamento de Ciências Biológicas - Universidade Federal de Lavras/UFLA Lavras, MG - evandenb@dbi.ufla.br, douglasc@dbi.ufla.br

${ }^{3}$ Engenheira Florestal, Professora Dra. em Engenharia Florestal - Instituto Federal de Educação, Ciência e Tecnologia do Sul de Minas Gerais - Campus Inconfidentes - Praça Tiradentes, 416, Centro - 37576-000 - Inconfidentes, MG - lilianvap@ gmail.com

${ }^{4}$ Engenheiro Florestal, Professor Dr. em Engenharia Florestal - Departamento de Engenharia Florestal - Centro de Ciências Agroveterinárias - Universidade do Estado de Santa Catarina - Av. Luiz de Camões, 2090, Conta Dinheiro - 88520-000 - Lages, SC higuchip@gmail.com

Cerne, Lavras, v. 16, n. 3, p. 305-321, jul./set. 2010 
vegetacionais muito heterogêneos entre si, de diferentes tamanhos, formas e conectividade (KAGEYAMA et al., 2003; VIANA \& PINHEIRO, 1998).

A intervenção humana tem ocasionado um efeito desestabilizador aos ecossistemas naturais, perturbando seu equilíbrio dinâmico. Dentre as alterações recentes que vêm ocorrendo nas florestas mundiais, destaca-se a fragmentação de remanescentes naturais em pedaços progressivamente menores, isolados por áreas tomadas pelo desenvolvimento agrícola, industrial e urbano (HARRIS, 1984). No processo de fragmentação dos habitats, a estrutura da paisagem é modificada, resultando em mudanças na composição e diversidade das comunidades, o que, segundo Reis et al. (2003), compromete a conservação in situ, já que a intensidade e o tipo de distúrbio influenciam diretamente o processo de restauração natural do ecossistema.

Os fragmentos florestais são áreas de vegetação natural, interrompidas por barreiras antrópicas ou naturais, capazes de diminuir significativamente o fluxo de animais, pólen e sementes. O processo de fragmentação implica ainda na redução da área, surgimento de borda, e redução de populações (ALVEREZ-BUYULLA et al., 1996; BERGALLO et al., 2000; LAURANCE et al., 1997; TOURNER, 1996; VIANA, 1990). A borda, o tipo de vizinhança, o grau de isolamento e o tamanho efetivo dos fragmentos são os principais fatores que devem ser considerados para medir as alterações dos processos biológicos de determinado ecossistema (VIANA, 1990). O isolamento dos fragmentos causa modificações profundas na dinâmica das populações de animais e vegetais (VIANA et al., 1992).

A área do campus da Universidade Federal de Lavras (UFLA) vem sendo ocupada por várias atividades produtivas ou de ordem arquitetônica. Em decorrência desse fato, a vegetação natural contida dentro dos limites da propriedade passou por um processo gradual de fragmentação. Não obstante essa perda de elementos bióticos, algumas iniciativas conservacionistas vêm possibilitando a regeneração da vegetação em algumas áreas protegidas. O conhecimento sobre os efeitos dessa fragmentação e da gradual recuperação desses ecossistemas é de interesse da comunidade científica da UFLA, bem como de seu corpo administrativo, tendo em vista a necessidade de se planejar e implantar, no âmbito de suas dependências, programas de gestão ambiental nos moldes do desenvolvimento sustentável e se adequar à legislação ambiental existente.

Cerne, Lavras, v. 16, n. 3, p. 305-321, jul./set. 2010
Conduziu-se este trabalho, com os objetivos de: a) mapear e caracterizar os principais fragmentos de vegetação natural existentes no domínio da UFLA, com a finalidade de subsidiar o estabelecimento de planos de gestão que minimizem os impactos ambientais nos fragmentos estudados, e (b) identificar áreas que sirvam como corredores, ou áreas que precisem ser recuperadas para cumprir esse papel, com potencial para maximizar a conectividade entre os fragmentos estudados.

\section{MATERIAL E MÉTODOS}

\subsection{Localização e caracterização das áreas de estudo}

Os fragmentos florestais estudados encontram-se situados no campus da Universidade Federal de Lavras UFLA, no município de Lavras, região sul do estado de Minas Gerais, entre as coordenadss UTM 7652332 e 7652603 de latitude sul e 502999 e 503122 de longitude oeste de Greenwich.

O clima do município de Lavras é do tipo Cwa, conforme a classificação climática de Köppen. A temperatura média anual está em torno de $19,3^{\circ} \mathrm{C}$, tendo, no mês mais quente e no mês mais frio, temperaturas médias de $22,1^{\circ} \mathrm{e}$ $15,8^{\circ}$, respectivamente. A precipitação anual normal é de $1.530 \mathrm{~mm}$, a evaporação total do ano igual a $1.343 \mathrm{~mm}$ e a umidade relativa média anual de 76\% (BRASIL, 1992). A vegetação primitiva pode ser considerada como transição entre Floresta Estacional Semidecidual Montana e Cerrado, e encontra-se atualmente, amplamente fragmentada e em diversos estádios serais.

\subsection{Metodologia de estudo}

Os fragmentos florestais remanescentes foram mapeados a partir da interpretação visual em meio digital imagens de satélite LANDSAT7 $-\mathrm{ETM}^{+}$de março de 2001, com resolução espacial 25 x 25m, e levantamento de campo. Foram utilizadas as bandas 3, 4 e 5, com os respectivos filtros B, G e R. Essas bandas passaram pela transformação IHS < > RGB, para que pudesse ser aproveitada a resolução de 12,5m da banda Pan (banda 8).

No tratamento e análise dos dados físicos dos fragmentos, procedeu-se à digitalização nos programas SPRING 3.4 e ENVI 3.5, como preparação para a entrada dos dados no programa FRAGSTATS 2.0. Esse programa se aplica à análise de padrões espaciais da paisagem e de fragmentos específicos. Neste estudo, os dados fornecidos pelo FRAGSTATS foram considerados como índices morfométricos. 
Os índices morfométricos utilizados para caracterizar os seis principais fragmentos (subestação, matinha, cerradinho, museu, angical e campo de futebol) e as três unidades de conectividade (área com eucalipto e regeneração de sub-bosque "administração", mancha de vegetação na área da psicultura e plantio de pinus e eucalipto) quanto à conservação da diversidade biológica do campus da UFLA foram: área, perímetro, índice de forma, área interna, número de áreas internas (NCA), índice de área interna, efeito de borda, distância do vizinho mais próximo (NND), índice de proximidade (IP) (BORGES et al., 2004; HERRMANN et al., 2005; METZGER, 1999; VOLOTÃO, 1998).

\subsubsection{Avaliação dos impactos}

Para a caracterização da ocupação dos seis principais fragmentos estudados e das três unidades que interligam os mesmos (plantios homogêneos de pinus e eucalipto, fragmento da psicultura, fragmento próximo ao departamento de administração, e angical) utilizou-se um questionário (matriz de impacto) para obter informações sobre os níveis de alterações dos mesmos. As linhas da matriz de interação dos impactos ambientais estão representadas pelos seis fragmentos e as três unidades de interligação avaliadas no questionário de campo e, as colunas, pelos impactos sofridos pelos mesmos ao longo do tempo. Seguindo a metodologia utilizada por Pereira et al. (2007), na última coluna da matriz foi lançado um valor sintético obtido a partir da soma dos valores atribuídos ao impacto multiplicado por pesos (valores) atribuídos para cada impacto. Esses pesos seguiram a valoração subjetiva adotada por Pereira (2003) e experiência de campo dos pesquisadores, assumindo os seguintes valores: $1=$ cerca (CE) e plantios homogêneos (PH); $2=$ lixo (LI), trilha (TR) e agricultura (AG); $3=$ estrada externa (EE) e pastagem (PA); $4=$ estrada interna (EI), gado (GA) e construções (CO); $5=$ fogo $(\mathrm{FG})$ e corte seletivo (CS); $6=$ corte raso $(\mathrm{CR})$.

\subsubsection{Avaliação do componente vegetal}

O levantamento florístico e estrutural da vegetação arbustivo-arbórea foi realizado no período de março a maio de 2003, por meio do método dos pontos quadrantes, conforme metodologia adotada por Martins (1991) e Rodrigues (1988). Para locação dos pontos, foram abertas linhas paralelas atravessando os remanescentes florestais no seu maior comprimento. A orientação das linhas foi feita com o auxílio de uma bússola. Nas linhas dos fragmentos subestação, matinha, cerradinho, angical e campo de futebol, a distância entre pontos foi de 20 metros, num total de 25 pontos por área. No fragmento do museu, em razão da área ser muito pequena, a distância entre os pontos amostrais foi de 10 metros, totalizando 11 pontos. Em cada quadrante, foi amostrado o indivíduo mais próximo do centro, com DAP (diâmetro a altura do peito) $\geq 5 \mathrm{~cm}$.

As espécies foram incluídas em famílias de acordo com o sistema Angiosperm Phylogeny Group - APG II (2003), sendo as identificações realizadas por meio de comparações a exsicatas depositadas no Herbário ESAL e consultas a especialistas e obras clássicas.

Para cada fragmento, calcularam-se os índices de diversidade de Shannon (H') e de equabilidade de Pielou (J') (KREBS, 1989) em base logarítmica natural (BROWER \& ZAR, 1984). A similaridade florística entre os fragmentos foi realizada por meio do índice de similaridade de Jaccard $(\mathrm{Sj})$.

\subsubsection{Análises multivariadas e correlações}

Para análise das correlações entre os impactos ambientais e a flora arbórea dos seis fragmentos estudados foi empregada uma análise de correspondência canônica (CCA) (TER BRAAK, 1987), utilizando-se o programa PCORD for Windows versão 4.14 (MCCUNE \& MEFFORD, 1999). Os dados utilizados para compor a matriz de ordenação foram os valores das pontuações dos impactos nos fragmentos e unidades de conectividade, multiplicados pelos seus respectivos pesos conforme detalhado no item 2.2. A CCA, diferentemente das demais análises indiretas, incorpora na ordenação as correlações e regressões entre dados florísticos e fatores ambientais, encontrando a combinação linear das variáveis ambientais que otimizam a dispersão das médias ponderadas das espécies (KENT \& COKER, 1992). Assim, a CCA é um método de ordenação direta, em que o resultado da ordenação é o produto da variabilidade dos dados ambientais e da variabilidade dos dados florísticos (KENT \& COKER, 1992; RODRIGUES et al., 2003).

De acordo com as recomendações de Ter Braak (1995), os valores de abundância foram transformados pela expressão $\log _{10}(a+1)$ para compensar os desvios causados por alguns poucos valores muito elevados. A matriz de abundância das espécies foi constituída do número de indivíduos por área das espécies que apresentaram cinco ou mais indivíduos na amostra total.

\section{RESULTADOS E DISCUSSÃO}

O campus da UFLA possui uma área de 505,2 hectares, dos quais 33,23 ha são consideradas áreas de Preservação Permanente, conforme o Código Florestal, Lei n. ${ }^{\circ} 4.771 / 65$ (Figura 1).

Cerne, Lavras, v. 16, n. 3, p. 305-321, jul./set. 2010 


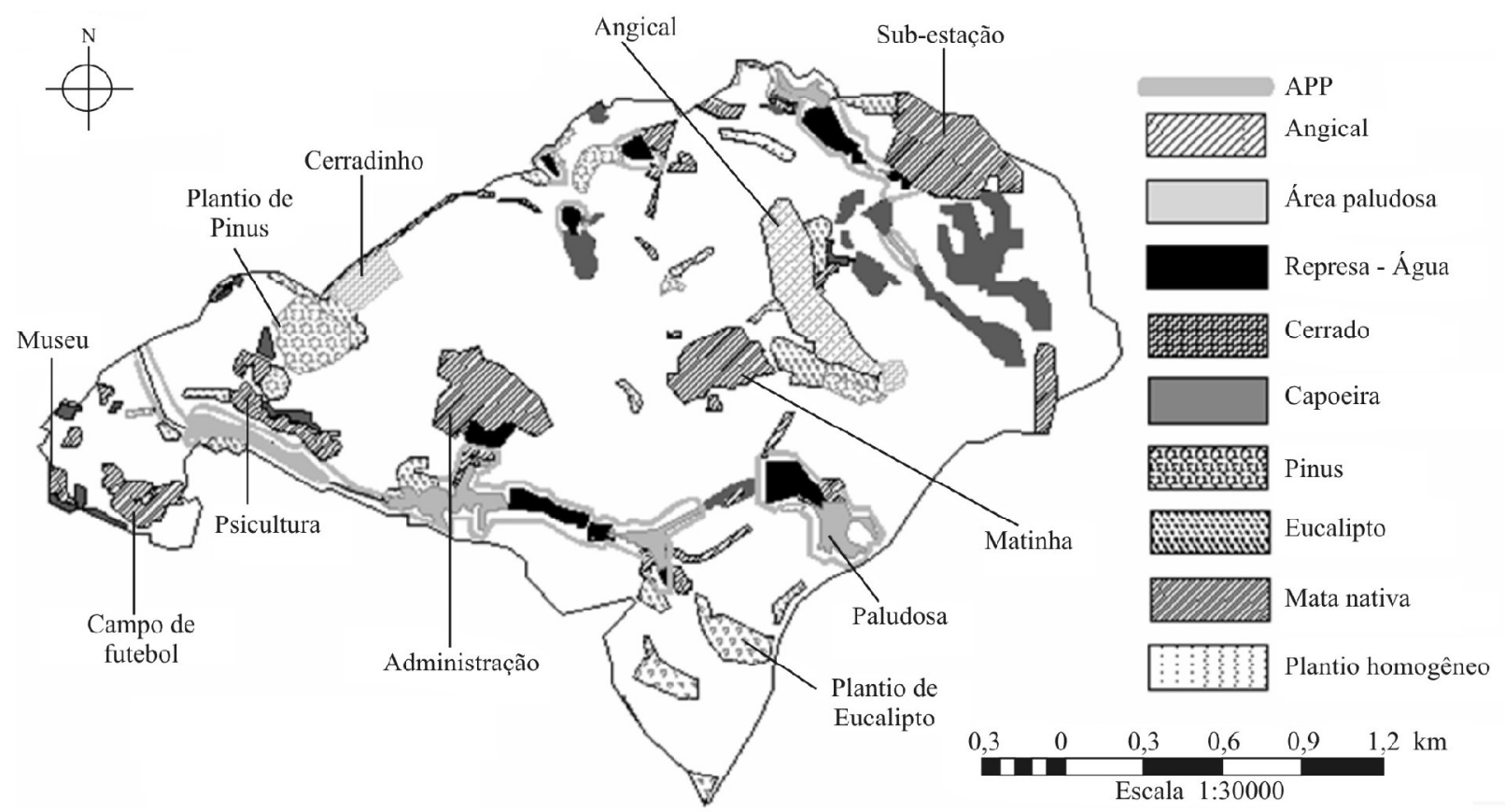

Figura 1 - Fragmentos e áreas de preservação permanente do campus da Universidade Federal de Lavras, Lavras, MG.

Figure 1 - Fragments and area of permanent preservation of the campus of the Federal University of Lavras, Lavras - MG.

De acordo com o mapa gerado neste trabalho a área ocupada com vegetação arbórea no Campus da UFLA é de 115,32 ha (Tabela 1). Deste total, 44,78 ha (38,83\%) são ocupados por mata nativa em estágio avançado de regeneração, 18,78 ha $(16,29 \%)$ são ocupados por plantios de eucalipto, 17,56 ha $(15,23 \%)$ por capoeiras em diferentes estágios sucessionais, 10,12 ha $(8,78 \%)$ por vegetação paludosa situadas ao redor das nascentes e ao longo dos cursos d'água, 10,02 ha $(8,69 \%)$ por plantio homogêneo de angico, 9,40 ha $(8,15 \%)$ por plantio de Pinus spp., 3,57 ha $(3,10 \%)$ por vegetação típica de cerrado e 1,09 ha $(0,95 \%)$ por plantio misto de espécies nativas.

Com base no mapa temático (Figura 1), verifica-se que a conectividade entre os fragmentos pode ser realizada por meio da manutenção e recuperação da vegetação nas áreas de preservação permanente, situadas ao longo dos cursos d'água e represas e isolamento dos fatores de degradação das principais unidades de conectividade, situada entre os fragmentos, além do enriquecimento das capoeiras com espécies de grupo ecológico mais avançado e condução da regeneração natural nas áreas com plantio homogêneo. Nessas áreas, faz-se necessária a eliminação dos fatores de degradação para que haja sucesso no restabelecimento da comunidade arbórea via regeneração natural. $\mathrm{O}$ anelamento de algumas árvores, para que haja penetração de luz direta no sub-bosque desses plantios, pode favorecer a germinação de sementes das espécies pioneiras presentes no banco de semente do solo.

Dessa forma, a manutenção ou restauração dessa vegetação pode promover o restabelecimento da conectividade da paisagem, por meio da interligação de fragmentos. Outra medida que pode ser utilizada para promover a conectividade é a construção de pequenos corredores por meio do plantio de espécies arbóreas em forma de pequenas faixas interligando os fragmentos. Castro (2004) evidencia a importância e eficiência dos corredores de valo na conservação da diversidade em escala regional e ressalta que estes podem ser indicados como uma técnica para tentar conectar porções de habitat remanescentes na região de Lavras, atuando na conservação da diversidade pouco representada nos fragmentos e contribuir para o estabelecimento de conexões entre os mesmos.

O total de vegetação, que pode ser considerado como reserva legal é de 105,20 ha (mata nativa, capoeira,

Cerne, Lavras, v. 16, n. 3, p. 305-321, jul./set. 2010 
cerrado, eucalipto, pinus, plantio nativo homogêneo e angical). Destes, 2,62 ha encontram-se dentro das APP, restando ainda, 102,5782 ha, valor que sustenta o exigido pela legislação, considerando-se que 101,04 ha (20\%) da área total deve ser de Reserva Legal. Assim, constata-se que a área com vegetação do Campus da UFLA, atende ao exigido pela legislação. No entanto, é necessário a implementação de medidas administrativas visando a minimizar os impactos antrópicos e promover condições ideais para perpetuação da biodiversidade nessas áreas.

Verificou-se que a soma dos seis principais fragmentos estudados totalizam 33,79 ha, que somada às áreas das três principais unidades de conectividade que interligam estes (plantios homogêneos de pinus e eucalipto, fragmento da psicultura e fragmento próximo ao departamento de administração), totalizam uma área de 52,28 hectares (Tabela 2).

Tabela 1 - Área total e distribuição percentual das classes dos fragmentos florestais mapeados no Campus da Universidade Federal de Lavras, Lavras - MG.

Table 1 - Total area and percentile distribution of the classes of the forest fragments mapped at the Campus of the Federal University of Lavras, Lavras - MG.

\begin{tabular}{lcc}
\hline Classe dos fragmentos & Área (ha) & $\%$ da área \\
\hline Mata nativa & 44,78 & 38,83 \\
Capoeira & 17,56 & 15,23 \\
Cerrado & 3,57 & 3,10 \\
Vegetação paludosa & 10,12 & 8,78 \\
Angical & 10,02 & 8,69 \\
Plantio nativo homogêneo & 1,09 & 0,95 \\
Eucalipto & 18,78 & 16,29 \\
Pinus & 9,40 & 8,15 \\
Total & 115,32 & 100,00 \\
\hline
\end{tabular}

Tabela 2 - Descrição morfométrica dos fragmentos florestais estudados no Campus da Universidade Federal de Lavras (UFLA$\mathrm{MG})$. Em que: $\mathrm{SE}=$ subestação, $\mathrm{MA}=$ matinha, $\mathrm{CE}=$ cerradinho, $\mathrm{MU}=$ museu, $\mathrm{AG}=$ angical, $\mathrm{CF}=\mathrm{campo}$ de futebol, $\mathrm{AD}=$ administração, $\mathrm{PC}=$ psicultura e $\mathrm{PPE}=$ plantio de pinus e eucalipto.

Table 2 - Morfometric Description of the forest fragments studied at the Campus of the Universidade Federal de Lavras (UFLA$M G$ ). Where: $\mathrm{SE}=$ substation, $\mathrm{MA}=$ Matinha, $\mathrm{EC}=$ cerradinho, $\mathrm{MU}=$ museum, $\mathrm{AG}=$ Angical, $\mathrm{CF}=$ fragment of the soccer field, $\mathrm{AD}=$ Administration, $\mathrm{PC}=$ pscicultura and $\mathrm{PPE}=$ planting pine and eucalyptus

\begin{tabular}{lccccccccc}
\hline \multirow{2}{*}{ Índices morfométricos } & \multicolumn{1}{c}{ Fragmentos/Unidades } \\
\cline { 2 - 9 } & SE & MA & CE & MU & AG & CF & AD & PC & PPE \\
\hline Área (ha) & 12,13 & 5,72 & 2,81 & 0,74 & 8,86 & 3,53 & 9,30 & 2,64 & 6,28 \\
Perímetro (m) & 2178 & 1476 & 994 & 590 & 2418 & 1854 & 2313 & 1676 & 1866 \\
Índice de forma & 1,56 & 1,48 & 1,48 & 1,72 & - & - & - & - & - \\
Área interna & 5,56 & 2,23 & 0,55 & 0 & - & - & - & - & - \\
Número de áreas internas & 1 & 1 & 1 & 0 & - & - & - & - & - \\
Índice de área interna & 45,80 & 35,97 & 19,67 & 0 & - & - & - & - & - \\
Efeito borda & 6,57 & 3,49 & 2,26 & 0,74 & - & - & - & - & - \\
Distância do vizinho mais & 260,08 & 88,27 & 0 & 77,77 & 88,27 & 77,77 & 206,92 & 116,82 & 0 \\
próximo (m) & & & & & & & & & \\
\hline
\end{tabular}


O maior valor obtido para área interna foi registrado para o fragmento da subestação (5,56 ha), seguido pelos fragmentos da matinha (2,23 ha) e cerradinho ( $0,55 \mathrm{ha})$. $\mathrm{O}$ fragmento do museu não apresentou nenhum núcleo de área interna, resultando no maior valor de efeito borda obtido $(0,74 \mathrm{ha})$, entre os quatro principais fragmentos estudados, o que corresponde a $100 \%$ da área do fragmento (Tabela 2). Quanto menor o índice de forma, mais arredondado é o fragmento, maior será a área interna, o que, consequentemente, reduz os riscos do interior do fragmento ser afetado pelo efeito de borda (BARROS FILHO, 1997; RANTA et al., 1998).

A distância mínima para os vizinhos mais próximos foi de $77,77 \mathrm{~m}$ para os fragmentos museu e campo de futebol; de 88,27 m para os fragmentos matinha e angico; de 188,67 para o fragmento da piscicultura; de $234,89 \mathrm{~m}$ para o cerradinho e o fragmento da administração; e de 260,08 m para o fragmento da subestação.

$\mathrm{O}$ isolamento de um fragmento pode afetar o fluxo de animais, pólen e sementes e, portanto, a diversidade biológica e a dinâmica das populações de plantas e animais (FORMAN \& GODRON, 1986). Segundo Bierregaard Junior et al. (1992), nem sempre o efeito do isolamento resultará na redução imediata da diversidade local, entretanto, em longo prazo, a riqueza de espécies em áreas fragmentadas tende a ser menor do que em áreas contínuas, tendo em vista que muitas das alterações ambientais após a fragmentação não são estáticas nem ocorrem de forma imediata (MALCOLM, 1991).

Os fragmentos estudados apresentam área muito pequena. Apenas um, apresentou área superior a $10 \mathrm{ha}$ (Subestação). Tais resultados confirmam que a paisagem na área do Campus da UFLA se assemelha às descritas em outros trabalhos em várias regiões do país, onde grande parte de vegetação remanescente encontra-se na forma de pequenos fragmentos isolados na paisagem (PEREIRA et al., 2007; RANTA et al., 1998; SANTIN, 1999).

Com relação à matriz de impacto (Tabela 3), verificase que na unidade de conectividade representada pelo povoamento de pinus e eucalipto foi onde constatou-se o maior impacto negativo da ação antrópica, principalmente, decorrente da ocorrência de fogo, contato com estrada externa de fluxo intenso, presença de trilhas, cercamento insuficiente, atividades agrícolas e outras ações antrópicas significativas. Necessita a adoção de medidas mitigadoras para que essa unidade possa exercer a função de conectividade dos fragmentos remanescentes, tais como construção de aceiros de combate a incêndios florestais, isolamento da área para transeuntes, além da adição de placas educativas conscientizando as pessoas a não jogarem lixo nessa área. Tais medidas objetivam minimizar os impactos e permitir que haja o processo de regeneração de espécies nativas por dispersão de propágulos vindos de outros fragmentos.

A flora arbórea dos seis principais fragmentos avaliados neste estudo foi representada por 544 indivíduos, 48 famílias, 160 espécies e 112 gêneros, assim distribuídos: Fragmento da subestação, com 24 famílias, 62 espécies e 50 gêneros; matinha, com 19 famílias, 31 espécies e 27 gêneros; cerradinho, com 19 famílias, 38 espécies e 32 gêneros; museu, 12 famílias, 16 espécies e 16 gêneros; angical 19 famílias, 30 espécies e 28 gêneros e campo de futebol, 26 famílias, 49 espécies e 41 gêneros (Tabela 4).

De modo geral, verifica-se que, aproximadamente, 67\% das espécies e 65\% dos indivíduos inventariados são disseminados por animais (zoocoria). Enquanto que 27\% das espécies e $30 \%$ dos indivíduos via anemocoria e apenas $6 \%$ das espécies e $5 \%$ dos indivíduos via autocoria.

O uso de espécies zoocóricas na implantação dos corredores, ou no enriquecimento dos povoamentos homogêneos e, ou capoeiras, pode contribuir para que haja uma maior integração entre os remanescente por meio da fauna.

O menor valor para o índice de diversidade de Shannon-Weaver (Tabela 5), foi registrado para o fragmento do museu $(2,135)$. Por outro lado, no fragmento da matinha obteve-se o maior índice de diversidade $(3,917)$.

Verifica-se, na Tabela 5, que os valores de equabilidade (J') variaram de 0,710 a 0,949 para as áreas do angical e matinha, respectivamente. Constata-se ainda que, os menores valores foram obtidos para o fragmento do museu e angical, evidenciando a existência de dominância ecológica de algumas espécies nestas áreas, como é o caso da Magnolia champaca no fragmento do museu, que possui $43 \%$ dos indivíduos amostrados e com ocorrência em $80 \%$ dos quadrantes, e Anadenanthera colubrina na no angical, que representam $44 \%$ dos indivíduos amostrados e que foi registrada em $60 \%$ dos quadrantes. A primeira, trata-se de uma espécie exótica plantada em áreas adjacentes que vem se propagando de forma agressiva neste fragmento que apresenta alto grau de perturbação antrópica. Enquanto que a segunda, é uma espécie nativa, colonizadora de grandes clareiras e de ampla plasticidade ecológica, ocorrendo em diferentes biomas e fitofisionomias. 
Tabela 3 - Matriz de impactos ambientais para os nove fragmentos florestais remanescentes estudados no Campus da Universidade Federal de Lavras, Lavras-MG. Em que: $\mathrm{Pa}=$ pastagem; $\mathrm{Ag}=$ agricultura, $\mathrm{Ph}=$ plantios homogêneos e $\mathrm{Co}=\mathrm{construções}$

Table 3 - Environmental impacts matrix for the nine remaining forest fragments studied at the Campus of the Federal University of Lavras, Lavras-MG. In the: $\mathrm{Pa}=$ pasture, $\mathrm{Ag}=$ agriculture, $\mathrm{Ph}=$ homogeneous plantations and Co=constructions.

\begin{tabular}{|c|c|c|c|c|c|c|c|c|c|c|c|c|c|c|}
\hline \multirow{3}{*}{ Fragmento } & \multicolumn{14}{|c|}{ Ações antrópicas } \\
\hline & \multirow{2}{*}{ Fogo } & \multirow{2}{*}{ Lixo } & \multirow{2}{*}{$\begin{array}{l}\text { Estrada } \\
\text { interna }\end{array}$} & \multirow{2}{*}{$\begin{array}{l}\text { Estrada } \\
\text { externa }\end{array}$} & \multirow{2}{*}{ Trilha } & \multirow{2}{*}{ Cerca } & \multirow{2}{*}{ Gado } & \multirow{2}{*}{$\begin{array}{c}\text { Corte } \\
\text { raso }\end{array}$} & \multirow{2}{*}{$\begin{array}{c}\text { Corte } \\
\text { seletivo }\end{array}$} & \multicolumn{4}{|c|}{ Matriz de entorno } & \multirow{2}{*}{$\mathrm{NF}$} \\
\hline & & & & & & & & & & $\mathrm{Pa}$ & $\mathrm{Ag}$ & $\mathrm{Ph}$ & $\mathrm{Co}$ & \\
\hline Peso & 5 & 2 & 4 & 3 & 2 & 1 & 4 & 6 & 5 & 3 & 2 & 1 & 4 & \\
\hline Subestação & 0 & 1 & 2 & 4 & 4 & 4 & 0 & 0 & 0 & 2 & 4 & 3 & 3 & 63 \\
\hline Matinha & 0 & 1 & 0 & 4 & 3 & 0 & 0 & 0 & 1 & 3 & 3 & 3 & 3 & 55 \\
\hline Cerradinho & 0 & 1 & 4 & 4 & 1 & 0 & 0 & 0 & 0 & 1 & 4 & 2 & 3 & 57 \\
\hline Museu & 0 & 4 & 0 & 4 & 4 & 1 & 0 & 0 & 4 & 0 & 0 & 0 & 4 & 65 \\
\hline Angical & 0 & 2 & 3 & 4 & 4 & 3 & 0 & 2 & 2 & 2 & 2 & 4 & 4 & 81 \\
\hline Campo futebol & 0 & 1 & 4 & 4 & 3 & 3 & 0 & 0 & 1 & 0 & 0 & 0 & 4 & 60 \\
\hline Administração & 0 & 1 & 3 & 4 & 3 & 4 & 0 & 0 & 1 & 4 & 2 & 2 & 4 & 75 \\
\hline Pisicultura & 1 & 4 & 4 & 4 & 3 & 4 & 0 & 0 & 0 & 3 & 2 & 2 & 4 & 82 \\
\hline Pinus + Eucalipto & 4 & 1 & 0 & 4 & 4 & 4 & 0 & 0 & 2 & 2 & 4 & 0 & 4 & 86 \\
\hline
\end{tabular}

$0=$ ausência; $1=$ baixo; $2=$ intermediário $3=$ alto; $4=$ muito alto.

Tabela 4 - Relação das espécies arbustivo-arbóreas dispostas em ordem alfabéticas de famílias amostradas em seis fragmentos remanescentes no Campus da Universidade Federal de Lavras, Lavras - MG. Em que: GE = Grupo Ecológico (Luz = espécie de luz e som = espécie de sombra; $\mathrm{SD}=$ síndrome de dispersão $(\mathrm{ane}=$ anemocórica, auto = autocórica e zôo = zoocórica; subestação, $\mathrm{MA}=$ matinha, $\mathrm{CE}=$ cerradinho, $\mathrm{MU}=$ museu, $\mathrm{AG}=$ angical, $\mathrm{CF}=$ campo de futebol e $\mathrm{NI}=$ número total de indivíduos.

Table 4 - Relation of the arbustive-arboreal species disposed in order alphabetical of families sampled in six remaining forest fragments studied at the Campus of the Federal University of Lavras, Lavras - MG. Where: EG =Ecological Group (Luz $=$ species of light and shadow = species of shadow, $D S=$ dispersion syndrome (Ane = anemochory, Auto $=$ autochory and zoo = zoochory; $S E=$ substation, $M A=$ Matinha, EC = cerradinho, $M U=$ museum, $A G=$ Angical, $C F=$ fragment of the football field and total number of individuals.

\begin{tabular}{|c|c|c|c|c|c|c|c|c|c|}
\hline \multirow{2}{*}{ Espécie/Família } & \multirow{2}{*}{ GE } & \multirow{2}{*}{ SD } & \multicolumn{6}{|c|}{ Fragmentos } & \multirow{2}{*}{$\mathrm{NI}$} \\
\hline & & & SB & MA & $\mathrm{CE}$ & MU & $\mathrm{AG}$ & $\mathrm{CF}$ & \\
\hline \multicolumn{10}{|l|}{ Anacardiaceae } \\
\hline Lithraea molleoides (Vell.) Engl. & Luz & Zoo & 0 & 0 & 0 & 0 & 1 & 2 & 3 \\
\hline Mangifera indica $\mathrm{L}$. & Luz & Zoo & 2 & 0 & 0 & 0 & 0 & 0 & 2 \\
\hline Schinus terebinthifolius Raddi & Luz & Zoo & 4 & 0 & 0 & 0 & 1 & 3 & 8 \\
\hline Tapirira guianensis Aubl. & Luz & Zoo & 0 & 0 & 0 & 0 & 0 & 6 & 6 \\
\hline Tapirira obtusa (Benth.) J.D.Mitch. & Luz & Zoo & 0 & 10 & 0 & 0 & 0 & 2 & 12 \\
\hline \multicolumn{10}{|l|}{ Annonaceae } \\
\hline Guatteria australis A.St.-Hil. & Som & Zoo & 0 & 0 & 0 & 4 & 0 & 0 & 4 \\
\hline Porcelia macrocarpa (Warm.) R.E.Fr. & Som & Zoo & 0 & 0 & 1 & 0 & 0 & 0 & 1 \\
\hline Rollinia laurifolia Schltdl. & Luz & Zoo & 0 & 0 & 1 & 0 & 1 & 0 & 2 \\
\hline
\end{tabular}


Tabela 4 - Continua...

Table 4 - Continued...

\begin{tabular}{|c|c|c|c|c|c|c|c|c|c|}
\hline \multirow{2}{*}{ Espécie/Família } & \multirow{2}{*}{ GE } & \multirow{2}{*}{$\mathrm{SD}$} & \multicolumn{6}{|c|}{ Fragmentos } & \multirow{2}{*}{$\mathrm{NI}$} \\
\hline & & & SB & MA & $\mathrm{CE}$ & MU & $\mathrm{AG}$ & $\mathrm{CF}$ & \\
\hline Annona sericea Dunal & Luz & Zoo & 0 & 3 & 0 & 0 & 0 & 0 & 3 \\
\hline Xylopia brasiliensis Spreng. & Som & Zoo & 0 & 6 & 0 & 0 & 2 & 0 & 8 \\
\hline \multicolumn{10}{|l|}{ Apocynaceae } \\
\hline Aspidosperma parvifolium A.DC. & Luz & Ane & 0 & 0 & 0 & 0 & 0 & 3 & 3 \\
\hline Aspidosperma tomentosum Mart. & Luz & Ane & 0 & 0 & 0 & 1 & 0 & 0 & 1 \\
\hline \multicolumn{10}{|l|}{ Aquifoliaceae } \\
\hline Ilex cerasifolia Reissek & Som & Zoo & 0 & 0 & 0 & 0 & 1 & 0 & 1 \\
\hline Ilex conocarpa Reissek & Luz & Zoo & 1 & 0 & 0 & 0 & 0 & 0 & 1 \\
\hline \multicolumn{10}{|l|}{ Araliaceae } \\
\hline Dendropanax cuneatus (DC.) Decne. \& Planch. & Som & Zoo & 4 & 0 & 0 & 0 & 0 & 0 & 4 \\
\hline Schefflera macrocarpa (Cham. \& Schltdl.) Frodin & Luz & Zoo & 0 & 0 & 0 & 0 & 0 & 1 & 1 \\
\hline \multicolumn{10}{|l|}{ Arecaceae } \\
\hline Syagrus romanzoffiana (Cham.) Glassman & Luz & Zoo & 0 & 0 & 0 & 0 & 1 & 0 & 1 \\
\hline \multicolumn{10}{|l|}{ Asteraceae } \\
\hline Gochnatia paniculata (Less.) Cabrera & Luz & Ane & 0 & 0 & 0 & 0 & 0 & 2 & 2 \\
\hline Gochnatia polymorpha (Less.) Cabrera & Luz & Ane & 0 & 0 & 0 & 2 & 0 & 0 & 2 \\
\hline Piptocarpha macropoda Baker & Luz & Ane & 0 & 1 & 0 & 0 & 0 & 0 & 1 \\
\hline \multicolumn{10}{|l|}{ Bignoniaceae } \\
\hline $\begin{array}{l}\text { Tabebuia aurea (Manso) Benth. \& Hook.f. ex } \\
\text { S.Moore }\end{array}$ & Luz & Ane & 0 & 0 & 0 & 3 & 0 & 0 & 3 \\
\hline Handroanthus impetiginosus (Mart. ex DC.) Mattos & Luz & Ane & 0 & 0 & 0 & 0 & 0 & 1 & 1 \\
\hline Handroanthus ochraceus (Cham.) Mattos & Luz & Ane & 0 & 0 & 0 & 2 & 0 & 0 & 2 \\
\hline Handroanthus umbellatus (Sond.) Mattos & Luz & Ane & 0 & 0 & 0 & 0 & 0 & 1 & 1 \\
\hline \multicolumn{10}{|l|}{ Boraginaceae } \\
\hline Cordia sellowiana Cham. & Luz & Zoo & 0 & 0 & 0 & 0 & 1 & 0 & 1 \\
\hline \multicolumn{10}{|l|}{ Burseraceae } \\
\hline Protium widgrenii Engl. & Luz & Zoo & 0 & 1 & 0 & 0 & 0 & 1 & 2 \\
\hline \multicolumn{10}{|l|}{ Celtidaceae } \\
\hline Celtis iguanaea (Jacq.) Sarg. & Luz & Zoo & 0 & 0 & 0 & 0 & 1 & 0 & 1 \\
\hline \multicolumn{10}{|l|}{ Chrysobalanaceae } \\
\hline Hirtella hebeclada Moric. & Som & Zoo & 0 & 1 & 0 & 0 & 0 & 0 & 1 \\
\hline \multicolumn{10}{|l|}{ Clusiaceae } \\
\hline Kielmeyera coriacea Mart. \& Zucc. & Luz & Ane & 0 & 0 & 0 & 1 & 0 & 0 & 1 \\
\hline Kielmeyera lathrophyton Saddi & Luz & Ane & 0 & 0 & 0 & 1 & 0 & 0 & 1 \\
\hline Kielmeyera variabilis Mart. \& Zucc. & Luz & Ane & 0 & 0 & 0 & 1 & 0 & 0 & 1 \\
\hline
\end{tabular}


Tabela 4 - Continua...

Table 4 - Continued...

\begin{tabular}{|c|c|c|c|c|c|c|c|c|c|}
\hline \multirow{2}{*}{ Espécie/Família } & \multirow{2}{*}{ GE } & \multirow{2}{*}{ SD } & \multicolumn{6}{|c|}{ Fragmentos } & \multirow{2}{*}{ NI } \\
\hline & & & SB & MA & $\mathrm{CE}$ & MU & $\mathrm{AG}$ & $\mathrm{CF}$ & \\
\hline \multicolumn{10}{|l|}{ Cunoniaceae } \\
\hline Lamanonia ternata Vell. & Luz & Ane & 0 & 1 & 0 & 0 & 0 & 0 & 1 \\
\hline \multicolumn{10}{|l|}{ Ebenaceae } \\
\hline Diospyros hispida A.DC. & Luz & Zoo & 0 & 0 & 0 & 2 & 0 & 0 & 2 \\
\hline \multicolumn{10}{|l|}{ Erythroxylaceae } \\
\hline Erythroxylum tortuosum Mart. & Luz & Zoo & 0 & 0 & 0 & 2 & 0 & 0 & 2 \\
\hline \multicolumn{10}{|l|}{ Euphorbiaceae } \\
\hline Actinostemon concolor (Spreng.) Müll.Arg. & Som & Zoo & 0 & 0 & 3 & 0 & 0 & 0 & 3 \\
\hline Alchornea glandulosa Poepp. \& Endl. & Luz & Zoo & 0 & 0 & 0 & 0 & 0 & 2 & 2 \\
\hline Croton floribundus Spreng. & Luz & Auto & 1 & 0 & 1 & 0 & 0 & 0 & 2 \\
\hline Maprounea guianensis Aubl. & Luz & Auto & 0 & 3 & 0 & 0 & 0 & 0 & 3 \\
\hline Sebastiania brasiliensis Spreng. & Som & Auto & 0 & 0 & 0 & 0 & 0 & 4 & 4 \\
\hline Sebastiania membranifolia Müll.Arg. & Som & Auto & 1 & 0 & 3 & 0 & 0 & 0 & 4 \\
\hline \multicolumn{10}{|l|}{ Fabaceae Caesalpinioideae } \\
\hline Bauhinia longifolia (Bong.) D.Dietr. & Luz & Auto & 1 & 0 & 5 & 1 & 0 & 0 & 7 \\
\hline Copaifera langsdorffii Desf. & Som & Zoo & 0 & 8 & 0 & 4 & 1 & 12 & 25 \\
\hline Peltophorum dubium (Spreng.) Taub. & Luz & Ane & 0 & 0 & 0 & 0 & 0 & 3 & 3 \\
\hline $\begin{array}{l}\text { Tachigali rugosa (Mart. ex Benth.) Zarucchi \& } \\
\text { Pipoly }\end{array}$ & Luz & Ane & 0 & 3 & 0 & 0 & 0 & 0 & 3 \\
\hline Senna multijuga (L.C.Rich.) H.S.Irwin \& Barneby & Luz & Auto & 0 & 0 & 0 & 0 & 0 & 1 & 1 \\
\hline Acosmium dasycarpum (Vogel) Yakovlev & Luz & Ane & 0 & 0 & 0 & 1 & 0 & 0 & 1 \\
\hline Bowdichia virgilioides Kunth & Luz & Ane & 0 & 0 & 0 & 12 & 0 & 0 & 12 \\
\hline Dalbergia miscolobium Benth. & Luz & Ane & 0 & 0 & 0 & 6 & 0 & 0 & 6 \\
\hline Dalbergia villosa (Benth.) Benth. & Luz & Ane & 0 & 0 & 1 & 0 & 0 & 0 & 1 \\
\hline Erythrina verna Vell. & Luz & Auto & 0 & 0 & 1 & 0 & 0 & 0 & 1 \\
\hline $\begin{array}{l}\text { Lonchocarpus cultratus (Vell.) Az.-Tozzi \& } \\
\text { H.C.Lima }\end{array}$ & Luz & Ane & 0 & 0 & 0 & 0 & 0 & 2 & 2 \\
\hline Machaerium brasiliense Vogel & Luz & Ane & 0 & 0 & 1 & 0 & 0 & 0 & 1 \\
\hline Machaerium hirtum (Vell.) Stellfeld & Luz & Ane & 0 & 0 & 0 & 0 & 0 & 2 & 2 \\
\hline Machaerium nictitans (Vell.) Benth. & Luz & Ane & 0 & 0 & 0 & 0 & 4 & 2 & 6 \\
\hline Machaerium stipitatum (DC.) Vogel & Luz & Ane & 0 & 1 & 1 & 0 & 0 & 0 & 2 \\
\hline Machaerium villosum Vogel & Luz & Ane & 0 & 0 & 1 & 0 & 7 & 2 & 10 \\
\hline Ormosia fastigiata Tul. & Luz & Zoo & 0 & 0 & 1 & 0 & 0 & 0 & 1 \\
\hline Platycyamus regnellii Benth. & Luz & Ane & 0 & 0 & 4 & 0 & 0 & 0 & 4 \\
\hline Platypodium elegans Vogel & Luz & Ane & 0 & 0 & 0 & 3 & 0 & 8 & 11 \\
\hline
\end{tabular}


Tabela 4 - Continua...

Table 4 - Continued...

\begin{tabular}{|c|c|c|c|c|c|c|c|c|c|}
\hline \multirow{2}{*}{ Espécie/Família } & \multirow{2}{*}{ GE } & \multirow{2}{*}{$\mathrm{SD}$} & \multicolumn{6}{|c|}{ Fragmentos } & \multirow{2}{*}{$\mathrm{NI}$} \\
\hline & & & SB & MA & $\mathrm{CE}$ & MU & AG & $\mathrm{CF}$ & \\
\hline \multicolumn{10}{|l|}{ Fabaceae Mimosoideae } \\
\hline Albizia polycephala (Benth.) Killip & Luz & Ane & 0 & 0 & 3 & 0 & 0 & 0 & 3 \\
\hline Anadenanthera colubrina (Vell.) Brenan & Luz & Ane & 0 & 0 & 0 & 0 & 44 & 2 & 46 \\
\hline Anadenanthera peregrina (L.) Speg. & Luz & Ane & 0 & 0 & 0 & 1 & 0 & 0 & 1 \\
\hline Anadenanthera macrocarpa (Benth.) Brenan & Luz & Ane & 0 & 0 & 3 & 0 & 0 & 0 & 3 \\
\hline Enterolobium schomburgkii Benth. & Luz & Zoo & 0 & 0 & 1 & 0 & 0 & 0 & 1 \\
\hline Inga marginata Willd. & Som & Zoo & 0 & 0 & 0 & 0 & 0 & 2 & 2 \\
\hline Inga striata Benth. & Luz & Zoo & 0 & 0 & 0 & 0 & 2 & 0 & 2 \\
\hline Inga vera Willd. & Luz & Zoo & 0 & 0 & 2 & 0 & 0 & 0 & 2 \\
\hline Piptadenia gonoacantha (Mart.) J.F.Macbr. & Luz & Auto & 0 & 0 & 1 & 0 & 2 & 0 & 3 \\
\hline $\begin{array}{l}\text { Leucochloron incuriale (Vell.) Barneby \& } \\
\text { J.W.Grimes }\end{array}$ & Luz & Auto & 0 & 0 & 0 & 1 & 0 & 0 & 1 \\
\hline Stryphnodendron adstringens (Mart.) Cov. & Luz & Zoo & 0 & 0 & 0 & 2 & 0 & 0 & 2 \\
\hline \multicolumn{10}{|l|}{ Hypericaceae } \\
\hline Vismia brasiliensis Choisy & Luz & Zoo & 0 & 0 & 1 & 0 & 0 & 0 & 1 \\
\hline \multicolumn{10}{|l|}{ Lamiaceae } \\
\hline Aegiphila sellowiana Cham. & Luz & Zoo & 1 & 0 & 0 & 1 & 0 & 1 & 3 \\
\hline \multicolumn{10}{|l|}{ Lauraceae } \\
\hline Cryptocarya aschersoniana $\mathrm{Mez}$ & Som & Zoo & 1 & 2 & 2 & 0 & 0 & 0 & 5 \\
\hline Endlicheria paniculata (Spreng.) J.F.Macbr. & Som & Zoo & 0 & 0 & 1 & 0 & 0 & 0 & 1 \\
\hline Nectandra grandiflora Nees & Som & Zoo & 0 & 0 & 1 & 0 & 0 & 0 & 1 \\
\hline Nectandra lanceolata Nees & Som & Zoo & 0 & 0 & 1 & 0 & 0 & 0 & 1 \\
\hline Nectandra megapotamica (Spreng.) Mez & Luz & Zoo & 0 & 0 & 1 & 1 & 0 & 0 & 2 \\
\hline Nectandra oppositifolia Nees & Som & Zoo & 0 & 0 & 0 & 0 & 3 & 0 & 3 \\
\hline Ocotea corymbosa (Meisn.) Mez & Luz & Zoo & 0 & 5 & 0 & 0 & 1 & 0 & 6 \\
\hline Ocotea laxa (Nees) Mez & Som & Zoo & 0 & 1 & 0 & 0 & 0 & 0 & 1 \\
\hline Ocotea odorifera (Vell.) Rohwer & Som & Zoo & 0 & 2 & 0 & 0 & 0 & 0 & 2 \\
\hline Persea willdenovii Kosterm. & Luz & Zoo & 0 & 1 & 1 & 0 & 2 & 0 & 4 \\
\hline \multicolumn{10}{|l|}{ Lecythidaceae } \\
\hline Cariniana estrellensis (Raddi) Kuntze & Som & Auto & 0 & 0 & 0 & 0 & 0 & 1 & 1 \\
\hline \multicolumn{10}{|l|}{ Loganiaceae } \\
\hline Strychnos brasiliensis (Spreng.) Mart. & Som & Zoo & 0 & 0 & 1 & 0 & 0 & 0 & 1 \\
\hline \multicolumn{10}{|l|}{ Magnoliaceae } \\
\hline Magnolia champaca $\mathrm{L}$. & Luz & Zoo & 19 & 0 & 0 & 0 & 0 & 0 & 19 \\
\hline
\end{tabular}

Cerne, Lavras, v. 16, n. 3, p. 305-321, jul./set. 2010 
Tabela 4 - Continua...

Table 4 - Continued...

\begin{tabular}{|c|c|c|c|c|c|c|c|c|c|}
\hline \multirow{2}{*}{ Espécie/Família } & \multirow{2}{*}{ GE } & \multirow{2}{*}{ SD } & \multicolumn{6}{|c|}{ Fragmentos } & \multirow{2}{*}{ NI } \\
\hline & & & SB & MA & $\mathrm{CE}$ & MU & AG & $\mathrm{CF}$ & \\
\hline \multicolumn{10}{|l|}{ Malpighiaceae } \\
\hline Banisteriopsis campestris (A. Juss.) Little & Luz & Ane & 0 & 0 & 0 & 1 & 0 & 0 & 1 \\
\hline Byrsonima laxiflora Griseb. & Luz & Zoo & 0 & 1 & 0 & 0 & 0 & 0 & 1 \\
\hline Byrsonima stipulacea A.Juss. & Luz & Zoo & 0 & 0 & 1 & 0 & 0 & 0 & 1 \\
\hline Byrsonima verbascifolia (L.) DC. & Luz & Zoo & 0 & 0 & 0 & 3 & 0 & 0 & 3 \\
\hline Heteropterys byrsonimifolia A.Juss. & Luz & Ane & 0 & 1 & 0 & 0 & 0 & 1 & 2 \\
\hline \multicolumn{10}{|l|}{ Malvaceae } \\
\hline Heliocarpus americanus $\mathrm{L}$. & Luz & Ane & 2 & 0 & 0 & 0 & 0 & 0 & 2 \\
\hline Luehea divaricata Mart. & Luz & Ane & 0 & 0 & 0 & 0 & 1 & 2 & 3 \\
\hline Luehea grandiflora Mart. \& Zucc. & Luz & Ane & 1 & 0 & 1 & 1 & 0 & 1 & 4 \\
\hline $\begin{array}{l}\text { Pseudobombax tomentosum (Mart. \& Zucc.) } \\
\text { A.Robyns }\end{array}$ & Luz & Ane & 0 & 0 & 0 & 1 & 0 & 0 & 1 \\
\hline \multicolumn{10}{|l|}{ Melastomataceae } \\
\hline Miconia albicans Triana & Luz & Zoo & 0 & 0 & 1 & 6 & 0 & 1 & 8 \\
\hline Miconia argyrophylla DC. & Luz & Zoo & 0 & 8 & 1 & 0 & 1 & 0 & 10 \\
\hline Miconia trianaei Cogn. & Luz & Zoo & 0 & 6 & 0 & 0 & 0 & 0 & 6 \\
\hline Tibouchina granulosa Cogn. & Luz & Ane & 0 & 0 & 1 & 0 & 0 & 0 & 1 \\
\hline \multicolumn{10}{|l|}{ Meliaceae } \\
\hline Cedrela odorata $\mathrm{L}$. & Luz & Ane & 2 & 0 & 0 & 0 & 0 & 0 & 2 \\
\hline Trichilia clausseni C.DC. & Som & Zoo & 0 & 0 & 1 & 0 & 0 & 0 & 1 \\
\hline Trichilia emarginata (Turcz.) C.DC. & Som & Zoo & 0 & 1 & 0 & 0 & 0 & 0 & 1 \\
\hline Trichilia pallida Sw. & Som & Zoo & 0 & 0 & 1 & 0 & 0 & 0 & 1 \\
\hline \multicolumn{10}{|l|}{ Memecylaceae } \\
\hline Mouriri glazioviana Cogn. & Luz & Zoo & 0 & 3 & 0 & 0 & 0 & 0 & 3 \\
\hline \multicolumn{10}{|l|}{ Monimiaceae } \\
\hline Mollinedia widgrenii A.DC. & Som & Zoo & 0 & 0 & 1 & 0 & 0 & 0 & 1 \\
\hline \multicolumn{10}{|l|}{ Moraceae } \\
\hline Maclura tinctoria (L.) Steud. & Luz & Zoo & 0 & 0 & 0 & 0 & 5 & 1 & 6 \\
\hline \multicolumn{10}{|l|}{ Myrsinaceae } \\
\hline Myrsine gardneriana A.DC. & Luz & Zoo & 0 & 1 & 0 & 0 & 0 & 0 & 1 \\
\hline Myrsine umbellata Mart. & Luz & Zoo & 0 & 0 & 0 & 2 & 0 & 1 & 3 \\
\hline \multicolumn{10}{|l|}{ Myrtaceae } \\
\hline Blepharocalyx salicifolius (Kunth) O.Berg & Som & Zoo & 0 & 1 & 0 & 0 & 0 & 0 & 1 \\
\hline Calycorectes acutatus (Miq.) Toledo & Som & Zoo & 0 & 0 & 3 & 0 & 0 & 0 & 3 \\
\hline Calyptranthes clusiifolia O.Berg & Som & Zoo & 1 & 2 & 0 & 0 & 1 & 0 & 4 \\
\hline
\end{tabular}


Tabela 4 - Continua...

Table 4 - Continued...

\begin{tabular}{|c|c|c|c|c|c|c|c|c|c|}
\hline \multirow{2}{*}{ Espécie/Família } & \multirow{2}{*}{ GE } & \multirow{2}{*}{$\mathrm{SD}$} & \multicolumn{6}{|c|}{ Fragmentos } & \multirow{2}{*}{ NI } \\
\hline & & & SB & MA & $\mathrm{CE}$ & MU & AG & $\mathrm{CF}$ & \\
\hline Corymbia citriodora Hill \& Johnson & Luz & Zoo & 0 & 0 & 0 & 0 & 0 & 1 & 1 \\
\hline Eugenia florida DC. & Som & Zoo & 0 & 0 & 2 & 0 & 0 & 1 & 3 \\
\hline Eugenia hyemalis Cambess. & Luz & Zoo & 0 & 0 & 0 & 0 & 0 & 1 & 1 \\
\hline Eugenia involucrata DC. & Luz & Zoo & 0 & 0 & 2 & 0 & 0 & 0 & 2 \\
\hline Eugenia pyriformis Cambess. & Luz & Zoo & 0 & 0 & 1 & 0 & 0 & 0 & 1 \\
\hline Hexachlamys edulis (O.Berg) Kausel \& D.Legrand & Som & Zoo & 0 & 0 & 0 & 3 & 0 & 0 & 3 \\
\hline Marlierea racemosa (Vell.) Kiaersk. & Luz & Zoo & 0 & 0 & 0 & 0 & 1 & 0 & 1 \\
\hline Myrcia splendens (Sw.) DC. & Luz & Zoo & 0 & 2 & 1 & 3 & 1 & 0 & 7 \\
\hline Myrcia multiflora (Lam.) DC. & Som & Zoo & 0 & 0 & 0 & 0 & 0 & 1 & 1 \\
\hline Myrcia rostrata DC. & Luz & Zoo & 0 & 0 & 2 & 0 & 2 & 1 & 5 \\
\hline Myrcia tomentosa (Aubl.) DC. & Luz & Zoo & 0 & 0 & 1 & 0 & 0 & 1 & 2 \\
\hline Myrcia variabilis DC. & Luz & Zoo & 0 & 0 & 0 & 3 & 0 & 0 & 3 \\
\hline Myrcia velutina $\mathrm{O}$. Berg & Som & Zoo & 0 & 0 & 0 & 1 & 0 & 0 & 1 \\
\hline Myrcia selloi (Spreng.) N.Silveira & Som & Zoo & 2 & 0 & 0 & 0 & 0 & 0 & 2 \\
\hline Myrciaria floribunda (H.West ex Willd.) O.Berg & Som & Zoo & 0 & 0 & 0 & 12 & 0 & 0 & 12 \\
\hline Psidium guajava $\mathrm{L}$ & Luz & Zoo & 0 & 0 & 0 & 0 & 0 & 1 & 1 \\
\hline Siphoneugena kuhlmannii Mattos & Som & Zoo & 0 & 2 & 0 & 0 & 0 & 0 & 2 \\
\hline Syzygium malaccensis (L.) Merr. \& Perry. & Som & Zoo & 0 & 0 & 1 & 0 & 0 & 0 & 1 \\
\hline \multicolumn{10}{|l|}{ Nyctaginaceae } \\
\hline Guapira hirsuta (Choisy) Lundell & Som & Zoo & 0 & 0 & 1 & 0 & 0 & 0 & 1 \\
\hline \multicolumn{10}{|l|}{ Polygonaceae } \\
\hline Coccoloba warmingii Meisn. & Luz & Zoo & 0 & 0 & 2 & 0 & 0 & 0 & 2 \\
\hline Triplaris gardneriana Weddell & Luz & Zoo & 0 & 0 & 2 & 0 & 0 & 0 & 2 \\
\hline \multicolumn{10}{|l|}{ Proteaceae } \\
\hline Roupala montana Aubl. & Luz & Ane & 0 & 0 & 3 & 0 & 0 & 0 & 3 \\
\hline \multicolumn{10}{|l|}{ Rhamnaceae } \\
\hline Rhamnidium elaeocarpum Reissek & Luz & Zoo & 0 & 0 & 1 & 0 & 0 & 0 & 1 \\
\hline \multicolumn{10}{|l|}{ Rosaceae } \\
\hline Prunus myrtifolia (L.) Urb. & Som & Zoo & 0 & 0 & 0 & 0 & 0 & 1 & 1 \\
\hline \multicolumn{10}{|l|}{ Rubiaceae } \\
\hline Cordiera concolor (Cham.) Kuntze & Luz & Zoo & 0 & 0 & 1 & 0 & 0 & 2 & 3 \\
\hline Amaioua guianensis Aubl. & Som & Zoo & 0 & 7 & 1 & 0 & 1 & 0 & 9 \\
\hline Faramea nigrescens Mart. & Som & Zoo & 0 & 0 & 1 & 0 & 0 & 0 & 1 \\
\hline Ixora gardneriana Benth. & Som & Zoo & 0 & 0 & 1 & 0 & 0 & 0 & 1 \\
\hline
\end{tabular}


Tabela 4 - Continua...

Table 4 - Continued...

\begin{tabular}{|c|c|c|c|c|c|c|c|c|c|}
\hline \multirow{2}{*}{ Espécie/Família } & \multirow{2}{*}{ GE } & \multirow{2}{*}{$\mathrm{SD}$} & \multicolumn{6}{|c|}{ Fragmentos } & \multirow{2}{*}{ NI } \\
\hline & & & SB & MA & $\mathrm{CE}$ & MU & AG & $\mathrm{CF}$ & \\
\hline Ixora brevifolia Benth. & Som & Zoo & 0 & 0 & 0 & 0 & 0 & 1 & 1 \\
\hline Rudgea jasminoides (Cham.) Müll.Arg. & Som & Zoo & 0 & 0 & 0 & 0 & 0 & 1 & 1 \\
\hline Rudgea viburnoides (Cham.) Benth. & Luz & Zoo & 0 & 0 & 0 & 1 & 0 & 0 & 1 \\
\hline \multicolumn{10}{|l|}{ Rutaceae } \\
\hline Balfourodendron riedelianum (Engl.) Engl. & Som & Zoo & 0 & 0 & 1 & 0 & 0 & 0 & 1 \\
\hline Zanthoxylum caribaeum Lam. & Luz & Zoo & 0 & 0 & 0 & 0 & 0 & 1 & 1 \\
\hline Zanthoxylum rhoifolium Lam. & Luz & Zoo & 0 & 0 & 1 & 0 & 0 & 0 & 1 \\
\hline \multicolumn{10}{|l|}{ Solonaceae } \\
\hline Solanum leucodendron Sendt. & Luz & Zoo & 0 & 0 & 0 & 0 & 1 & 0 & 1 \\
\hline \multicolumn{10}{|l|}{ Salicaceae } \\
\hline Casearia arborea (L.C.Rich.) Urb. & Luz & Zoo & 0 & 9 & 0 & 0 & 0 & 0 & 9 \\
\hline Casearia lasiophylla Eichler & Luz & Zoo & 1 & 0 & 1 & 0 & 2 & 1 & 5 \\
\hline Casearia sylvestris $\mathrm{Sw}$. & Luz & Zoo & 0 & 5 & 7 & 1 & 7 & 0 & 20 \\
\hline \multicolumn{10}{|l|}{ Sapindaceae } \\
\hline Cupania vernalis Cambess. & Luz & Zoo & 0 & 0 & 6 & 0 & 0 & 0 & 6 \\
\hline Matayba elaeagnoides Radlk. & Luz & Zoo & 0 & 0 & 2 & 0 & 1 & 0 & 3 \\
\hline \multicolumn{10}{|l|}{ Sapotaceae } \\
\hline Chrysophyllum marginatum (Hook. \& Arn.) Radlk. & Luz & Zoo & 0 & 0 & 1 & 0 & 0 & 8 & 9 \\
\hline \multicolumn{10}{|l|}{ Siparunaceae } \\
\hline Siparuna cujabana (Mart.) A.DC. & Som & Zoo & 0 & 0 & 0 & 0 & 0 & 1 & 1 \\
\hline Siparuna guianensis Aubl. & Som & Zoo & 0 & 2 & 2 & 0 & 1 & 0 & 4 \\
\hline \multicolumn{10}{|l|}{ Styracaceae } \\
\hline Styrax camporus Pohl & Luz & Zoo & 0 & 0 & 0 & 3 & 0 & 1 & 4 \\
\hline Styrax ferrugineus Nees \& Mart. & Luz & Zoo & 0 & 0 & 0 & 1 & 0 & 0 & 1 \\
\hline \multicolumn{10}{|l|}{ Urticaceae } \\
\hline Cecropia pachystachya Trécul & Luz & Zoo & 0 & 0 & 1 & 0 & 0 & 1 & 2 \\
\hline \multicolumn{10}{|l|}{ Verbenaceae } \\
\hline Cytharexylum myrianthum Cham. & Luz & Zoo & 0 & 0 & 1 & 0 & 0 & 0 & 1 \\
\hline \multicolumn{10}{|l|}{ Vochysiaceae } \\
\hline Callisthene fasciculata (Spreng.) Mart. & Luz & Ane & 0 & 0 & 0 & 1 & 0 & 0 & 1 \\
\hline Qualea grandiflora Mart. & Luz & Ane & 0 & 0 & 0 & 5 & 0 & 0 & 5 \\
\hline Vochysia tucanorum Mart. & Luz & Ane & 0 & 0 & 0 & 0 & 0 & 1 & 1 \\
\hline Total & & & 44 & 100 & 100 & 100 & 100 & 100 & 544 \\
\hline
\end{tabular}


Tabela 5 - Valores de riqueza, abundância, diversidade e equabilidade para seis fragmentos remanescentes no Campus da Universidade Federal de Lavras, Lavras-MG.

Table 5 - Richness, abundance, diversity and equality to six remaining forest fragments studied at the Campus of the Federal University of Lavras, Lavras-MG.

\begin{tabular}{lcccc}
\hline & & & \multicolumn{2}{c}{ Índices } \\
\cline { 4 - 5 } Fragmentos & Número de espécies & Número de indivíduos & $\begin{array}{c}\text { Diversidade de Shannon } \\
\text { Weaver (H') }\end{array}$ & $\begin{array}{c}\text { Equabilidade de } \\
\text { Pielou }\left(\mathrm{J}^{\prime}\right)\end{array}$ \\
\hline Subestação (I) & 62 & 100 & 3,917 & 0,949 \\
Matinha (II) & 31 & 100 & 3,117 & 0,908 \\
Cerradinho (III) & 38 & 100 & 3,289 & 0,904 \\
Museu (IV) & 16 & 44 & 2,135 & 0,770 \\
Angical (V) & 30 & 100 & 2,416 & 0,710 \\
Campo (VI) & 49 & 100 & 3,546 & 0,911 \\
\hline
\end{tabular}

A similaridade obtida entre os seis fragmentos, conforme observa-se na Tabela 6, foi baixa. Segundo Kent \& Coker (1992), valores de similaridade inferiores a 50\% podem ser considerados baixos. Tal fato pode ser consequência dos diferentes níveis de perturbação em que os fragmentos se encontram, bem como da comparação entre fragmentos em diferentes formatos, tamanho, grau de antropismo, estádios sucessionais, nível de isolamento, diferentes fisionomias, origens e históricos de perturbação. Mesmo assim, a maior similaridade foi registrada entre o angical e a matinha $(\mathrm{Ij}=19,40 \%)$, fragmentos que apresentam distância mínima entre fragmentos de $88,25 \mathrm{~m}$, distância menor do que a encontrada para os fragmentos da administração, subestação e piscicultura.

Possivelmente, a matinha tenha sido a principal fonte de propágulos para o processo de colonização do sub-bosque do angical, ao longo dos anos. Aubert \& Oliveira Filho (1994), estudando a regeneração natural no sub-bosque de povoamentos de Pinus spp., e Eucalyptus spp. no Campus da UFLA, também contaram uma forte influência das matas circunvizinhas.

Os resultados da análise de correspondência canônica (CCA) estão representados nos diagramas de ordenação da Figura 2, verificou-se, então, que a CCA produziu alta correlação espécie-ambiente nos dois primeiros eixos: 1,00 (eixo 1) e 0,994 (eixo 2). Os impactos ambientais mais fortemente correlacionadas com o primeiro eixo de ordenação foram, presença de estradas internas, trilhas e corte seletivo (Figura 2a).

Cerne, Lavras, v. 16, n. 3, p. 305-321, jul./set. 2010
Na Figura 2b, constata-se que a ordenação das espécies pela CCA resultou na formação de quatro grupos distintos. O primeiro foi formado por espécies como Bowdichia virgilioides, Dalbergia miscolobium, Myrciaria floribunda e Qualea grandiflora ordenadas no canto inferior esquerdo (Figura 2b). Essas espécies foram exclusivas ou ocorreram de forma mais abundantes no fragmento do cerradinho, que apresenta fisionomia típica de cerrado.

O segundo grupo foi formado pelas espécies Schinus terebinthifolius e Magnolia champaca, ordenadas na parte superior direita do gráfico. Tais espécies foram exclusivas ou ocorreram de forma mais abundantes no fragmento do museu, onde constatouse o maior número de impactos. Já, o terceiro grupo foi formado pelas espécies Tapirira guianensis, Chrysophyllum marginatum, Copaifera langsdorffii, Cryptocarya aschersoniana, Myrcia rostrata, Myrcia fallax, Cupania vernalis ordenadas na parte central do gráfico. Essas espécies foram exclusivas ou ocorreram de forma mais abundantes nos fragmentos subestação e campo de futebol. O quarto grupo foi representado por espécies como Tapirira obtusa, Xylopia brasiliensis, Ocotea corymbosa, Miconia trianae, Maclura tinctoria, Amaioua guianensis, Casearia arborea, Casearia sylvestris, Miconia argyrophylla, Anadenanthera colubrina, Machaerium villosum, Machaerium nictitans, ordenadas no canto inferior direito do gráfico. Tais espécies foram exclusivas ou ocorreram de forma mais abundantes nos fragmentos da matinha e no angical. 
Tabela 6 - Matriz florística das seis áreas situadas no Campus da Universidade Federal de Lavras, Lavras-MG, mostrando o número de espécies em comum entre as áreas na metade superior direita e os índices de similaridade de Jaccard (\%) na metade inferior esquerda.

Table 6 - Floristic matrix of the six located areas in the Campus of the Federal University of Lavras, Lavras-MG, showing the number of species among the areas in the right superior half and the index of similarity of Jaccard (\%) in the left inferior.

\begin{tabular}{lcccccc}
\hline Fragmentos & Subestação (I) & Matinha (II) & Cerradinho (III) & Museu (IV) & Angical (V) & Campo (VI) \\
\hline Subestação (I) & - & 8 & 6 & 6 & 12 & 10 \\
Matinha (II) & 9,41 & - & 3 & 2 & 10 & 4 \\
Cerradinho (III) & 6,38 & 4,55 & - & 3 & 3 & 7 \\
Museu (IV) & 8,33 & 4,44 & 5,88 & - & 3 & 4 \\
Angical (V) & 15,00 & 19,40 & 4,62 & 6,98 & - & 10 \\
Campo (VI) & 9,90 & 5,26 & 8,75 & 6,56 & 14,19 & - \\
\hline
\end{tabular}
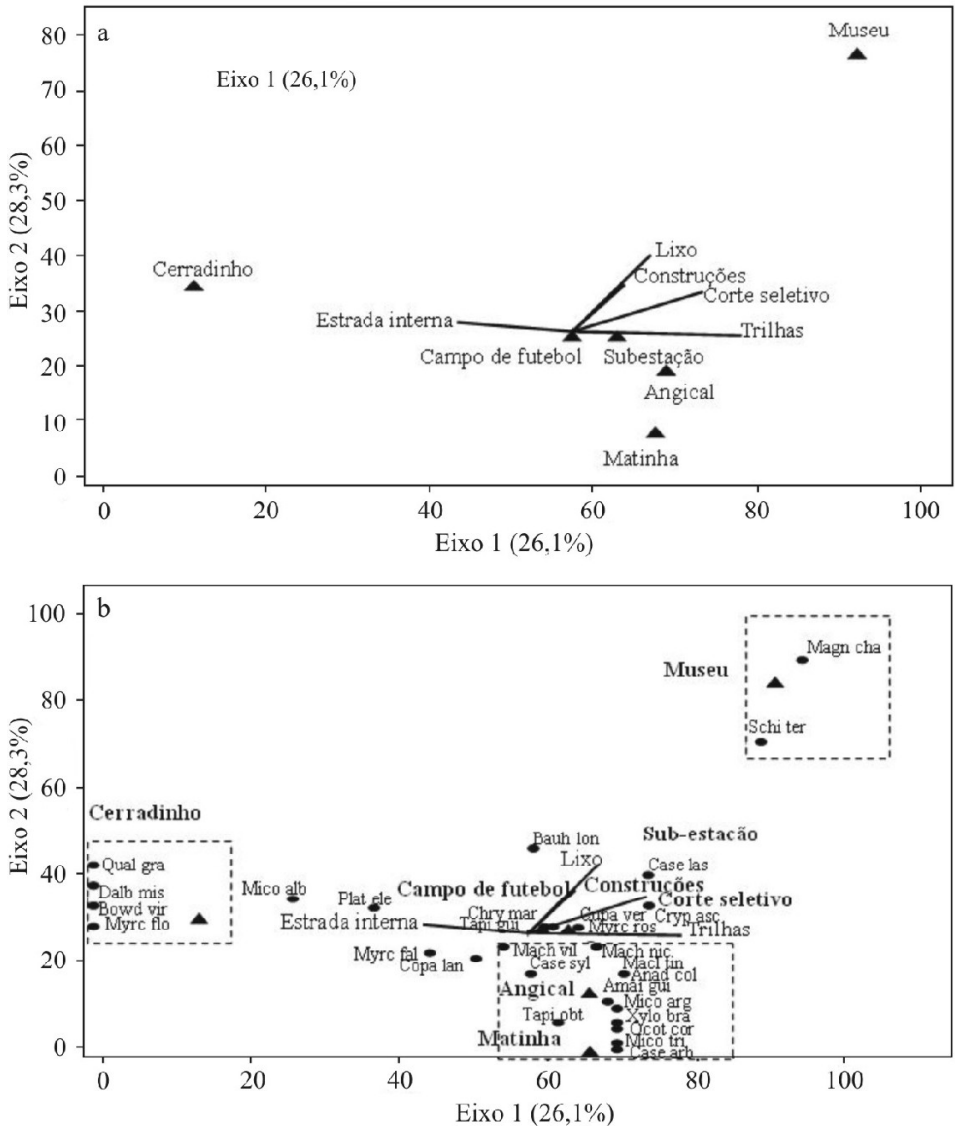

Figura 2 - Diagrama de ordenação dos fragmentos e impactos (a) e espécies (b) produzidos pela análise de correspondência canônica (CCA) da distribuição do número de indivíduos de 29 espécies arbóreas em seis fragmentos remanescentes no Campus da Universidade Federal de Lavras, Lavras-MG.

Figure 2 - Diagram of ordination of the fragments $(a)$ and species $(b)$ produced by the analysis of correspondence (CCA) of the distribution of the number of individuals of 29 arboreal species in six remaining fragments in the Campus of the Federal University of Lavras, Lavras-MG.

Cerne, Lavras, v. 16, n. 3, p. 305-321, jul./set. 2010 


\section{CONCLUSÕES}

inferir:

De acordo com os resultados obtidos, foi possível

- Os impactos presença de lixo, trilhas internas e ausência de cerca ou presença de cerca inadequada foram constatados em todos os remanescentes avaliados;

- O fragmento do museu e a unidade de conectividade de plantio homogêneo de pinus e eucalipto foram os locais onde contatou-se os impactos negativos mais severos, promovidos, principalmente, pela presença de lixo e ocorrência de incêndios florestais, sendo necessária a adoção de medidas urgentes para eliminar esses impactos e tornas a conectividade efetiva entre os remanescentes;

- Os remanescentes da UFLA, apesar dos impactos sofridos ainda detêm uma elevada diversidade, o que demanda ações de planejamento na implantação de futuras construções de forma a minimizar os impactos ambientais.

- A conectividade entre os fragmentos remanescentes do campus da UFLA pode ser realizada por meio da recuperação e manutenção das áreas de preservação permanente ao longo dos cursos d'água e condução da regeneração natural no interior dos plantios homogêneos e das áreas de capoeiras.

- É necessário, além da adoção das medidas técnicas supracitadas, a implantação de ações de educação ambiental, tendo como público alvo a comunidade universitária e a comunidade circunvizinha, a respeito da importância da preservação desses remanescentes para a conservação da biodiversidade.

\section{REFERÊNCIAS BIBLIOGRÁFICAS}

ALVEREZ-BUYULLA, E. R.; GARCIA-BARRIOS, R.; LARA-MORENO, C.; MARTINEZ-RAMOS, M. Demographic and genetics models in conservation biology: Applications and perspectives for tropical rain forest tree species. Annual Review for Ecology and Systematic, Palo Alto, v. 27, p. $387-721,1996$.

ANGIOSPERM PHYLOGENY GROUP. An update of the Angiosperm Phylogeny Group classification for the orders and families of flowering plants: APG II. Botanical Journal of the Linnean Society, London, v. 141, n. 4, p. 399-436, Apr. 2003.

AUBERT, E.; OLIVEIRA-FILHO, A. T. Analise multivariadada da estrutura fitossociologica do sub-bosque de plantios experimentais de Eucalyptus spp. e Pinus spp. em Lavras (MG). Revista Árvore, Viçosa, v. 18, n. 3, p. 194-214, 1994.

Cerne, Lavras, v. 16, n. 3, p. 305-321, jul./set. 2010
BARROS FILHO, L. Fragmentos florestais nativos: estudo de paisagem em domínio de floresta Atlântica, município de Itabira, MG. 1997. 55 p. Dissertação (Mestrado em Ciência Florestal) - Universidade Federal de Viçosa, Viçosa, 1997.

BERGAllO, H. G.; ROCHA, C. F. D.; ALVES, M. A. S.; SLUYS, M. V. A fauna ameaçada de extinção do Estado do Rio de Janeiro: Rio de Janeiro: UERJ, 2000. 166 p.

BIERREGAARD JUNIOR, R. O.; LOVEJOY, T. E.; KAPOS, V.; SANTOS, A. A.; HUTCHINGS, R. W. The biological dynamics of tropical rain forest fragments. Bioscience, Washington , v. 42, n. 11, p. 859-866, 1992.

BORGES, L. F. R.; SCOLFORO, J. R.; OLIVEIRA, A. D.; MELLO, J. M.; ACERBI JUNIOR, F. W.; FREITAS, G. D. Inventário de fragmentos florestais nativos e propostas para seu manejo e o da paisagem. Cerne, Lavras, v. 10, n. 1, p. 22-38, jan./ jun. 2004.

BRASIL. Ministério da Agricultura e Reforma Agrária. Normais climatológicas 1961-1990. Brasília, 1992. 84 p.

BROWER, J. E.; ZAR, J. H. Field and laboratory methods for general ecology. Dubuque: W.M.C. Brown, 1984. 84 p.

CASTRO, G. C. Análise da estrutura, diversidade florística e variações espaciais do componente arbóreo de corredores de vegetação na região do Alto Rio Grande, MG. 2004. 82 p. Dissertação (Mestrado em Engenharia Florestal) - Universidade Federal de Lavras, Lavras, 2004.

FORMAN, R. T. T.; GODRON, M. Landscape ecology. New York: J. Wiley, 1986. 619 p.

HARRIS, L. D. The fragmented forest: the island biogeography theory and the preservation of biotic diversity. Chicago: University of Chicago, 1984. $211 \mathrm{p}$.

HERRMANN, B. C.; RODRIGUES, E.; LIMA, A. Paisagem como condicionadora de bordas de fragmentos florestais. Floresta, Curitiba, v. 35, n. 1, jan./abr. 2005.

KAGEYAMA, P. Y.; GANDARA, F. B.; OLIVEIRA, R. E. Biodiversidade e restauração da floresta tropical. In: KAGEYAMA, P. Y. (Ed.). Restauração ecológica de ecossistemas naturais. Botucatu: FEPAF, 2003. p. 27- 48. 
KENT, M.; COKER, P. Vegetation description and analysis, a practical approach. London: Belhaven, 1992. 215 p.

KREBS, C. J. Ecological methodology. New York: Harper and Row, 1989.

LAURANCE, W. F.; BIEREEGAARD, R.; MORITZ, C.; VIANA, V. M. Tropical forest remnants: synthesis of a dynamic and eclectic. In: BIEREEGAARD, R.; LAURANCE, W. F. (Eds.). Tropical forest remnants: ecology, management and conservation of fragments community. Chicago: Chicago University, 1997. p. 9-15.

MALCOLM, J. R. The small mammals of Amazonian forest fragments: patterns and process. 1991. Thesis (PhD) University of Florida, Gainesville.

MARTINS, F. R. Estrutura de uma floresta mesófila. Campinas: Unicamp, 1991. 245 p.

MCCUNE, B.; MEFFORD, M. J. PC-ORD version 4. 0 : Multivariate analysis of ecological data: users guide. Glaneden Beach: MjM Software Design, 1999. 148 p.

METZGER, J. P. Estrutura da paisagem e fragmentação: análise bibliográfica. Anais da Academia Brasileira de Ciência, Rio de Janeiro, v. 71, n. 3, p. 445-463, 1999.

PEREIRA, J. A. A. Efeitos dos impactos ambientais e da heterogeneidade ambiental sobre a diversidade e estrutura da comunidade arbórea de 20 fragmentos de florestas semidecíduas da região do Alto Rio Grande, Minas Gerais. 2003. 156 p. Tese (Doutorado em Ecologia, Conservação e Manejo da Vida Silvestre) - Universidade Federal de Minas Gerais, Belo Horizonte, 2003.

PEREIRA, J. A. A.; OLIVEIRA-FILHO, A. T.; LEMOS-FILHO, J. P. Environmental heterogeneity and disturbance by humans control much of the tree species diversity of Atlantic montane forest fragments in SE Brazil. Biodiversity and Conservation, New York, v. 16, n. 6, p. 1761-1784, 2007.

RANTA, P.; BLOM, T.; NIEMELA, J.; JOENSUU, E.; SIITONEM, M. The fragmented in Atlantic rain forest of Brazil: size, shape and distribution of forest fragmented. Biodiversity and Conservation, New York, v. 7, n. 3, p. 385-403, 1998.

REIS, A.; BECHARA, F. C.; ESPINDOLA, M. B.; VIEIRA, N. K.; SOUZA, L. L. de. Restauração de áreas degradadas: a nucleação como base para incrementar os processos sucessionais. Natureza \& Conservação, Curitiba, v. 1, n. 1, p. 28-36, 2003.

RODRIGUES, L. A.; CARVALHO, D. A.; OLIVEIRA-FILHO, A. T.; BOTREL, R. T.; SILVA, E. A. Florística e estrutura da comunidade arbórea de um fragmento florestal em Luminárias, MG. Acta Botanica Brasílica, Rio de Janeiro, v. 17, n. 1, p. 71-97, 2003.

RODRIGUES, R. R. Metodos fitossociologicos mais usados. Casa da Agricultura, Campinas, v. 10, n. 1, p. 20-24, 1988.

SANTIN, D. A. A vegetação remanescente do município de Campinas (SP): mapeamento, caracterização fisionômica e florística, visando a conservação. 1999. 400 p. Tese (Doutorado em Biologia Vegetal) - Universidade Estadual de Campinas, Campinas, 1999.

TER BRAAK, C. J. F. The analysis of vegetation-environment relationships by canonical correspondence analysis. Vegetatio, Netherlands, v. 69, n. 1, p. 69-77, 1987.

TER BRAAK, C. J. F. Ordination. In: JONGMAN, R. H. G.; TER BRAAK, C. J. F.; TONGEREN, O. F. R. van (Eds.). Data analysis in community and landscape ecology. Cambridge: Cambridge University, 1995. p. 91-173.

TOURNER, I. M. Species loss in fragments of tropical rain forest: a review of the evidence. Journal of Applied Ecology, Oxford, v. 33, n. 2, p. 200-209, 1996.

VIANA, V. M. Biologia e manejo de fragmentos florestais naturais. In: CONGRESSO FLORESTAL BRASILEIRO, 6., 1990, Campos do Jordão. Anais... Campos do Jordão: SBS/SBEF, 1990. v. 1 , p. $113-118$.

VIANA, V. M.; PINHEIRO, L. A. F. V. Conservação da biodiversidade em fragmentos florestais. Piracicaba: IPEF, 1998. 42 p. (Seria técnica IPEF, 12).

VIANA, V. M.; TABANEZ, A. J. A.; MARTINEZ, J. L. A. Restauração e manejo de fragmentos florestais. In: CONGRESSO NACIONAL SOBRE ESSÊNCIAS NATIVAS, 2., 1992, Campos do Jordão. Anais... Campos do Jordão: Instituto Florestal, 1992. p. 400-406.

VOLOTÃO, C. F. S. Trabalho de análise espacial: métricas do Fragstats. 1998. 45 p. Dissertação (Mestrado em Análise Espacial) - Instituto Nacional de Pesquisas Espacial, São José dos Campos, 1998.

Cerne, Lavras, v. 16, n. 3, p. 305-321, jul./set. 2010 